\title{
Bilateral atresia of the external acoustic meatus: a case report
}

\author{
Ekrem Solmaz $^{1}$ (D), Mehmet Öztürk² (D), Zeliha Fazlığulları ${ }^{1}$ (D), Betül Sevindik ${ }^{1}$ (D), \\ Nadire Ünver Doğan ${ }^{1}$ \\ ${ }^{1}$ Department of Anatomy, School of Medicine, Selçuk University, Konya, Turkey \\ ${ }^{2}$ Department of Radiology, School of Medicine, Selçuk University, Konya, Turkey
}

\begin{abstract}
Bilateral atresia of the external acoustic meatus is a rare condition. It is a subtype of congenital aural atresia, which comprises a spectrum of developmental ear abnormalities. In this case report, we present the computed tomography (CT) findings of a patient with this congenital anomaly and emphasize the importance of the findings with regard to treatment options. CT revealed bilateral atresia of the external acoustic meatus in coronal and axial sections of an 8-year-old boy was admitted to hospital due to hearing loss. No congenital anomaly was detected in the middle and inner ear structures. Early detection of congenital aural atresia is critical. Speech retardation and accompanying anomalies associated with hearing loss may be seen in these patients. CT is essential for the diagnosis and classification of congenital bilateral aural atresia, identification of concomitant ear anomalies, and determination of the appropriate surgical treatment method.
\end{abstract}

Keywords: computed tomography; ear anomaly; external acoustic meatus

Anatomy 2020;14(1):72-75 @2020 Turkish Society of Anatomy and Clinical Anatomy (TSACA)

\section{Introduction}

Congenital aural atresia (CAA) is a developmental anomaly that includes auricular, external acoustic meatus, and middle ear deformities. ${ }^{[1]}$ In CAA, embryologically, the epithelial plate of the first branchial groove fails to canalize. ${ }^{[2]}$ CAA is seen in 1 per 10,000-20,000 live births, and it is more common in males. Unilateral atresia is five times more common than bilateral atresia. ${ }^{[3]}$ Altmann ${ }^{[4]}$ classified CAA as per severity evaluated based on pathology and symptoms as follows: mild (Grade I) CAA is characterized by mild malformation of external acoustic meatus, malformation of the auditory ossicles, and good mastoid pneumatization; moderate (Grade II) CAA, by the absence of the external acoustic meatus, malformation of the auditory ossicles, and poor mastoid pneumatization; and severe (Grade III) CAA, by the absence of the external acoustic meatus, malformation of the auditory ossicles, and lack of mastoid pneumatization. In CAA, hearing loss is conductive. Early diagnosis is crucial because speech development depends on hearing. Computed tomography (CT) is required for the evaluation of external acoustic meatus, a subtype of CAA, since otoscopic examination is unsuitable in case of external ear hypoplasia or atresia. ${ }^{[5]}$ Inner ear functions are generally normal. Conductive hearing loss can be corrected by surgical intervention at an appropriate age ${ }^{[6]}$ Here, we describe the CT findings in bilateral atresia of external acoustic meatus and emphasize their importance with regard to treatment options.

\section{Case Report}

An 8-year-old boy was admitted to our faculty hospital because of bilateral hearing loss. Informed consent of the patient's family was obtained before CT examination. CT images revealed bilateral atresia of external acoustic meatus in coronal and axial sections (Figures 1 and 2). No congenital anomaly was detected in the middle and inner ear. The auditory ossicles were normal. Mastoid pneumatization was adequate (Figure 3). Although these findings did not fully comply with Altmann's classification, they were categorized as moderate (Grade II) CAA due to the absence of the external acoustic meatus and the presence of mastoid pneumatization..$^{[4]}$ 

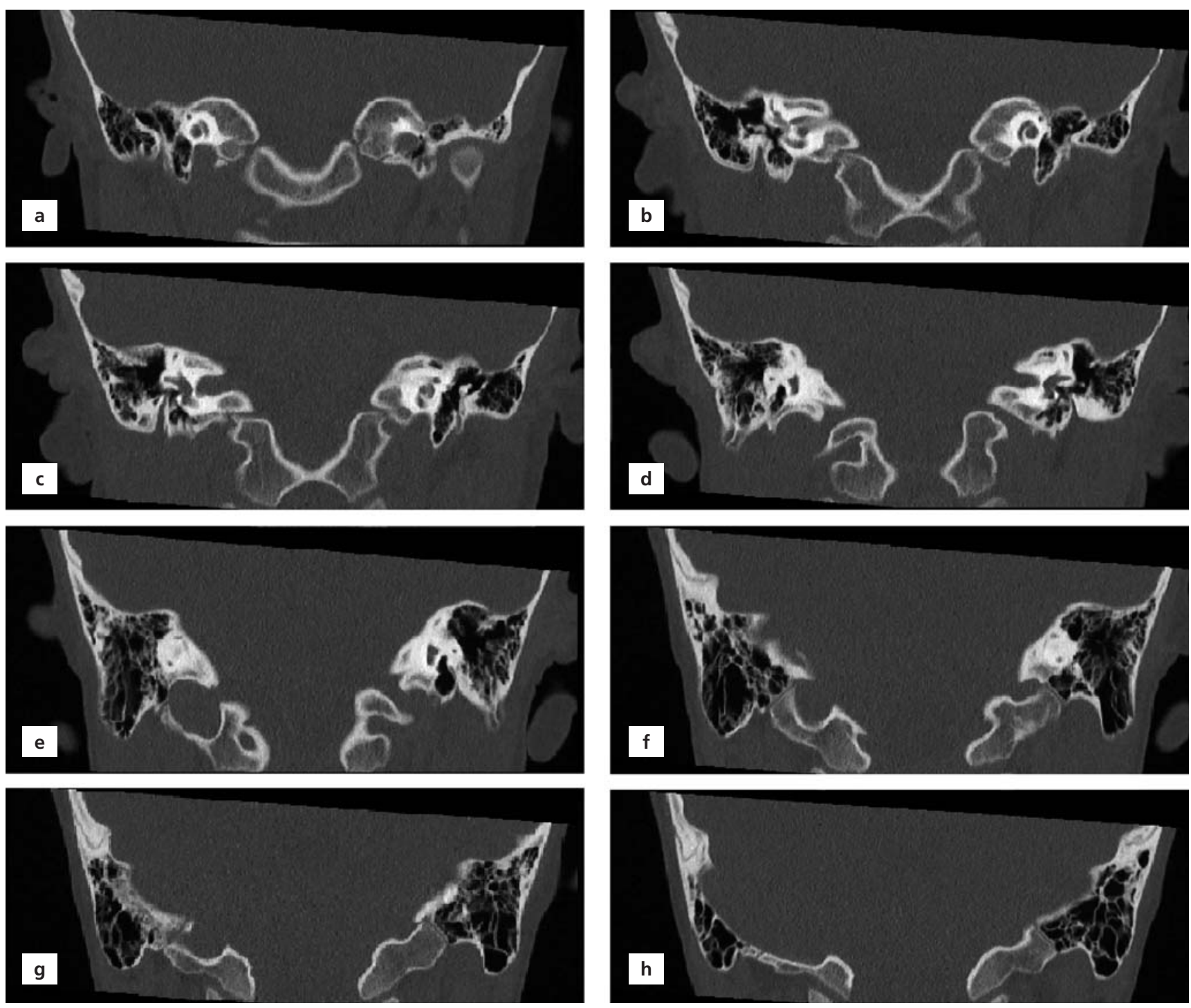

Figure 1. Coronal thin-section CT scans $(\mathbf{a}-\mathbf{h})$. The continuity of the atresia of the external acoustic meatus can be followed in sequential sections.

\section{Discussion}

CAA may show autosomal recessive inheritance, but is generally sporadic. It can be accompanied with DiGeorge, VATER, Klippel-Feil, Fanconi, Pierre Robin, and CHARGE syndromes. Concomitant anomalies include cleft palate, hemifacial microsomia, posterior cranial hypoplasia, hydrocephalus, and genitourinary abnormalities. ${ }^{[3]}$ None of these anomalies was observed in our patient.

Colman $^{[7]}$ divided patients with CAA with conductive hearing loss into three groups. The first group includes those with narrow but open external acoustic meatus; the second group with completely closed external acoustic meatus and complex anomalies in the middle ear; and the third group with severe external acoustic meatus malformation and no mastoid pneumatization. Our patient presented with hearing loss, but the findings did not match any of the groups in the Colman's classification; only external ear canal atresia was observed.

Schuknecht ${ }^{[8]}$ divided CAA into four types based on choosing the right surgical technique and evaluating important findings at the time of surgery: Type A includes atresia in the fibrocartilaginous part of the external acoustic meatus; Type B includes stenosis of the external acoustic meatus and malformation of the auditory ossicles; Type C includes complete atresia of external acoustic meatus and good mastoid pneumatization; Type D includes complete atresia of external acoustic meatus and poorly pneumatized middle ear. The findings in our patient were entirely consistent with Type C CAA.

A 10-point scale was developed by Jahrsdoerfer et al. ${ }^{[9]}$ by evaluating the anatomical structures in the temporal bone using high-resolution CT, and this system is key for 

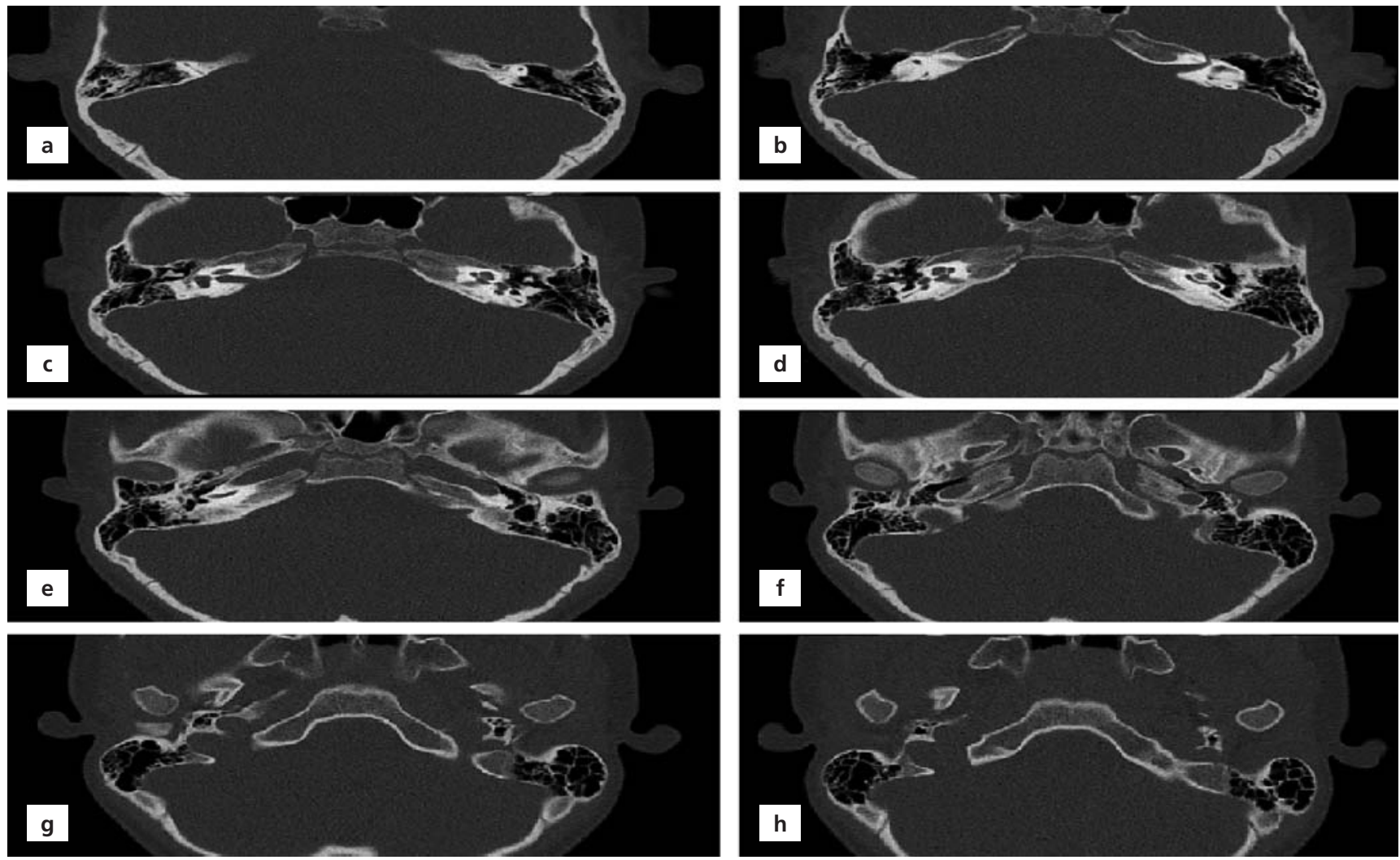

Figure 2. Axial thin-section CT scans ( $\mathbf{a}-\mathbf{h})$. The continuity of the atresia of the external acoustic meatus can be followed in sequential sections.
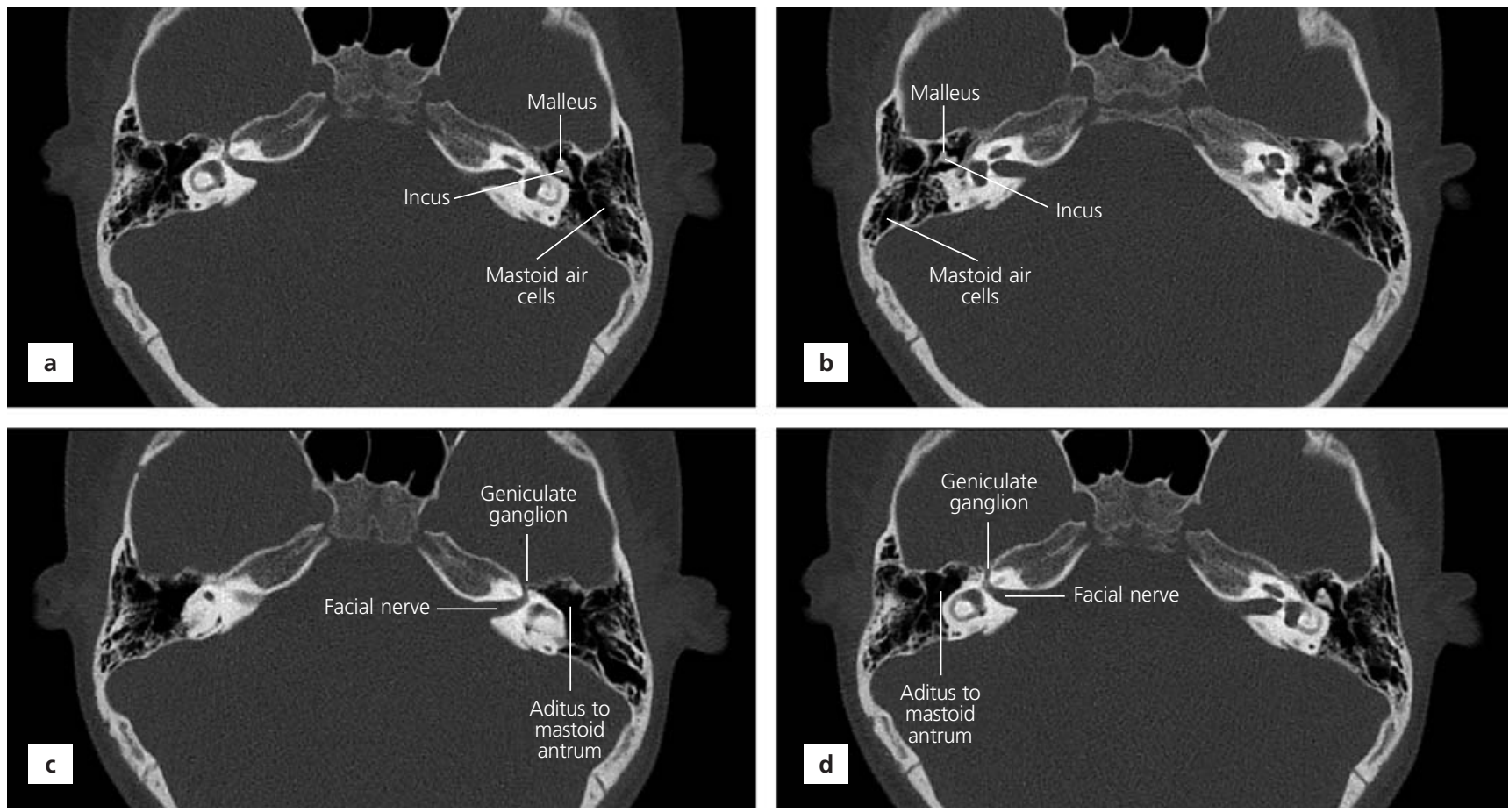

Figure 3. Axial thin-section CT scans (a-d). (a) Mastoid pneumatization and auditory ossicles are normal on the left side; (b) mastoid pneumatization and auditory ossicles are normal on the right side; (c) presence of aditus to mastoid antrum and facial nerve (labyrinthine segment) on the left side; (d) presence of aditus to mastoid antrum and facial nerve (labyrinthine segment) on the right side. 
preoperative decision-making. ${ }^{[9]}$ In another study, a 28point scale was developed by evaluating the anatomical structures examined to determine prognosis after surgery. ${ }^{[10]}$ Since only bilateral atresia of external acoustic meatus was present in our patient and no abnormalities were noted in other structures, the Jahrsdoerfer score (9) with the modified Siegert score (26) were high and these high scores indicate an excellent postoperative prognosis..$^{[9,10]}$

A study modified Altmann's classification and considered conditions such as poor mastoid pneumatization, malformation of the fenestra vestibuli, and abnormal course of the facial nerve as major anomalies and the absence of these conditions as minor anomalies. ${ }^{[11]}$ In our patient, only minor malformations were seen.

High-resolution CT allows a detailed examination of the middle ear, bony structures, and the course of the facial nerve in the temporal bone, and essential information can be obtained before surgical intervention. ${ }^{[6]}$ The goal of surgery is to provide a good level of hearing and establish an open and noninfectious external acoustic meatus. ${ }^{[12]}$ In our patient, CT findings revealed only bilateral atresia of external acoustic meatus. No congenital anomaly was detected in the middle and inner ear structures; the auditory ossicles were normal, and mastoid pneumatization was good. In light of these findings, an excellent postoperative outcome was expected.

Bilateral atresia is usually corrected at 4 or 5 years of age regardless of the presence of an auricular deformity. In patients with unilateral atresia, surgery can be postponed until young adulthood or nonsurgical recommendations can be made. Correction of auricular deformities is generally performed before atresia repair. ${ }^{[13]}$

In this case, CT of the 8-year-old patient with hearing loss was taken to detect anomaly of the external acoustic meatus and other pathologies. Detailed image analysis was performed to determine the appropriate treatment option for the surgeon. We evaluated it as a teaching case with CT results.

CT is essential for the detection and evaluation of congenital anomalies of the middle ear, and inner ear in children with atresia of external acoustic meatus, and the results obtained are essential in surgical candidate evaluation and surgery planning.

\section{Author Contributions}

ES: designing, evaluation of the data, writing text, MO: image acquisition and analysis, evaluation of the data, ZF: designing, evaluation of the data, writing text, BS: evaluation of the data, writing text, NUD: writing text, final check of the manuscript.

\section{References}

1. Spring PM, Gianoli GJ. Congenital aural atresia. J La State Med Soc 1997;149:6-9.

2. Bellucci RJ. Congenital aural malformations: diagnosis and treatment. Otolaryngol Clin North Am 1981;14:95-124.

3. Tubbs RS, Shoja MM, Loukas M (eds). Bergman's comprehensive encyclopedia of human anatomic variation. Hoboken (NJ): John Wiley \& Sons; 2016. p. 1173-75.

4. Altmann F. Congenital atresia of the ear in man and animals. Ann Otol Rhinol Laryngol 1955;64:824-58.

5. Mayer TE, Brueckmann H, Siegert R, Witt A, Weerda H. High-resolution CT of the temporal bone in dysplasia of the auricle and external auditory canal. AJNR Am J Neuroradiol 1997;18:53-65.

6. Jahrsdoerfer RA. Congenital atresia of the ear. Laryngoscope 1978; $88: 1-48$.

7. Colman B. Congenital atresia of the ear: the otological problem. Proc R Soc Med 1974;67:1203.

8. Schuknecht HF. Congenital aural atresia. Laryngoscope 1989;99: 908-17.

9. Jahrsdoerfer RA, Yeakley JW, Aguilar EA, Cole RR, Gray LC. Grading system for the selection of patients with congenital aural atresia. Am J Otol 1992;13:6-12.

10. Siegert R, Weerda H, Mayer T, Brückmann H. High resolution computerized tomography of middle ear abnormalities. Laryngorhinootologie 1996;75:187-94.

11. De la Cruz A, Teufert KB. Reconstruction of the auditory canal and tympanum. In: Richardson MA, Flint PW, Haughey BH, Lund VJ, Niparko JK, Robbins KT, Thomas JR, editors. Cummings otolaryngology head and neck surgery. 5th ed. Vol. 3. Philadelphia (PA): Elsevier Mosby; 2010. p. 2752-60.

12. Teufert KB, De La Cruz A. Advances in congenital aural atresia surgery: effects on outcome. Otolaryngol Head Neck Surg 2004;131: 263-70.

13. Swartz JD, Faerber EN. Congenital malformations of the external and middle ear: high-resolution CT findings of surgical import. AJR Am J Roentgenol 1985;144:501-6.
ORCID ID:

E. Solmaz 0000-0002-5091-0251; M. Öztürk 0000-0001-5585-1476; Z. Fazlıoğulları 0000-0002-5103-090X; B. Sevindik 0000-0003-1287-5544; N. Ünver Doğan 000-0001-5696-5547

\author{
Correspondence to: Zeliha Fazlıoğulları, PhD \\ Department of Anatomy, School of Medicine, Selçuk University, \\ 42130, Konya, Turkey \\ Phone: +902722463301 \\ e-mail: z_topal@yahoo.com \\ Conflict of interest statement: No conflicts declared.
}

This is an open access article distributed under the terms of the Creative Commons Attribution-NonCommercial-NoDerivs 3.0 Unported (CC BY-NCND3.0) Licence (http://creativecommons.org/licenses/by-nc-nd/3.0/) which permits unrestricted noncommercial use, distribution, and reproduction in any medium, provided the original work is properly cited. Please cite this article as: Solmaz E, Öztürk M, Fazlığulları Z, Sevindik B, Ünver Doğan N. Bilateral atresia of the external acoustic meatus: a case report. Anatomy 2020;14(1):72-75. 